\title{
Investigations on Optimal Pulse-Width Modulation to Minimize Total Harmonic Distortion in the Line Current
}

\author{
Avanish Tripathi*, Student Member, IEEE, G. Narayanan ${ }^{\dagger}$, \\ Department of Electrical Engineering, Indian Institute of Science, Bangalore - 560012 INDIA \\ Email: * avanish@ee.iisc.ernet.in; ${ }^{\dagger}$ gnar@ee.iisc.ernet.in
}

\begin{abstract}
PWM waveforms with positive voltage transition at the positive zero crossing of the fundamental voltage (type-A) are generally considered for PWM waveform with even number of switching angles per quarter whereas, waveforms with negative voltage transition at the positive zero crossing (type-B) are considered for odd number of switching angles per quarter. Optimal PWM, for minimization of total harmonic distortion of line to line $\left(V_{W T H D}\right)$, is generally solved with the aforementioned criteria. This paper establishes that a combination of both types of waveforms gives better performance than any individual type in terms of minimum $V_{W T H D}$ for complete range of modulation index $(M)$. Optimal PWM for minimum $V_{W T H D}$ is solved for PWM waveforms with pulse numbers $(P)$ of 5 and 7 . Both type-A and type-B waveforms are found to be better in different ranges of $M$. The theoretical findings are confirmed through simulation and experimental results on a $3.7 \mathrm{~kW}$ squirrel cage induction motor in an open-loop $V / f$ drive. Further, the optimal PWM is analysed from a space vector point of view.

Index Terms-Harmonic analysis, harmonic distortion, induction motor drive, off-line pulse width modulation, optimal pulse width modulation, voltage-source inverter.
\end{abstract}

\section{INTRODUCTION}

The ratio of switching frequency to fundamental frequency (i.e. pulse number, $P$ ) is constrained to be low for highpower motor drives on account of high switching losses [1][5]. Also, in case of high-speed motor drives, $P$ is low due to high fundamental frequency [6]. Fig.1 shows two typical pole voltage waveforms $\left(v_{R O}\right)$, measured between the R-phase terminal and the dc bus mid-point $\mathrm{O}$, having a pulse number of 5. Both waveforms possess half-wave and quarter-wave symmetries [7][8]. Apart from the switching transitions at $\theta=0^{\circ}$ and $\theta=180^{\circ}$, there are two switching angles (i.e. $\alpha_{1}$ and $\alpha_{2}$ ) in each quarter cycle in both waveforms.

The pole voltage waveform in Fig. 1(a) has a switching transition from $\frac{-V_{d c}}{2}$ to $\frac{+V_{d c}}{2}$ at the positive zero-crossing of the R-phase fundamental voltage, i.e. $\theta=0^{\circ}$. This is termed as type-A PWM waveform. On the other hand, the pole voltage waveform in Fig. 1(b) switches from $\frac{+V_{d c}}{2}$ to $\frac{-V_{d c}}{2}$ at $\theta=$ $0^{\circ}$. This is termed as type-B PWM waveform. To design a high-performance pulse width modulation (PWM) scheme for

This work is funded by the Department of Heavy Industry, Government of India, under a project titled "Off-line and Real-time Simulators for Electric Vehicle/ Hybrid Electric Vehicle Systems.”

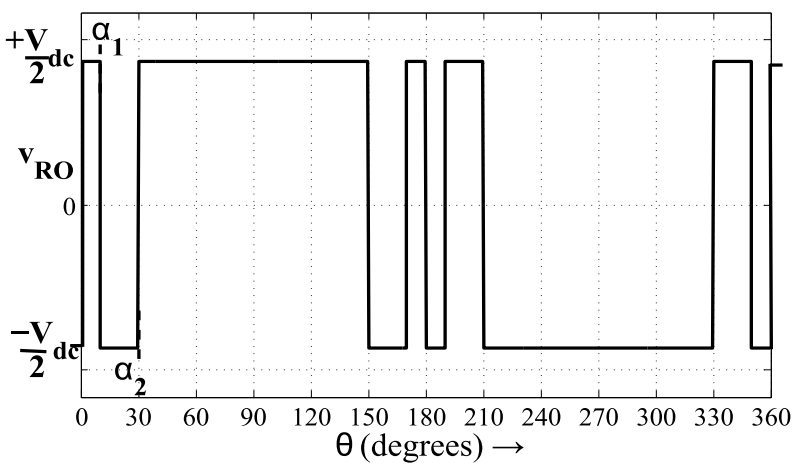

(a)

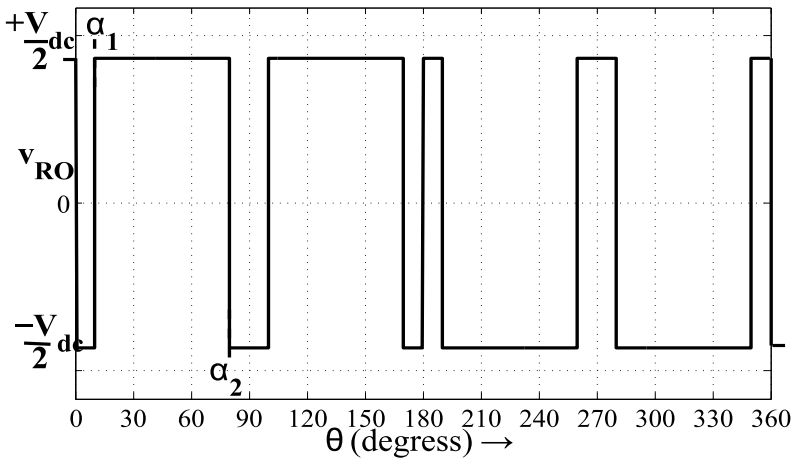

(b)

Fig. 1. Illustration of pole voltage at low inverter switching frequency (pulse number 5) (a) type A waveform and (b) type B waveform

any pulse number $P$, the motor drive engineer has to decide between type-A and type-B waveforms.

In literature, type-A waveform is considered to yield good quality waveform when the number of switching angles per quarter is even. Similarly, type-B is regarded as the better choice for odd number of switching angles per quarter [11]. This paper studies the relative performances and suitability of type-A and type-B waveforms in detail as discussed below.

This paper first investigates optimal type-A PWM and optimal type-B PWM to minimize the total harmonic distortion (THD) in line current $\left(I_{T H D}\right)$ for $P=5$ and $P=7$. Considering type-A and $P=5$, for example, switching angles are solved so as to yield the desired fundamental voltage and 


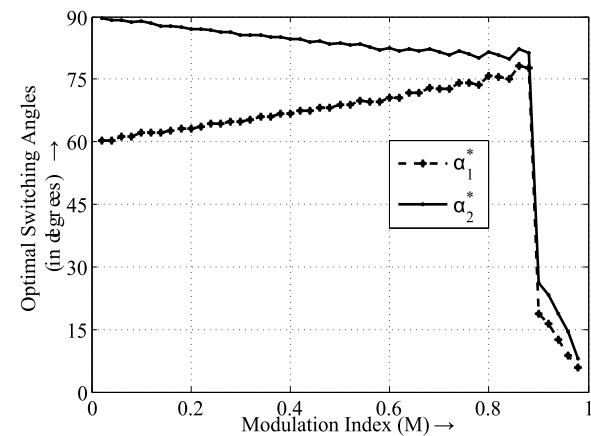

(a)

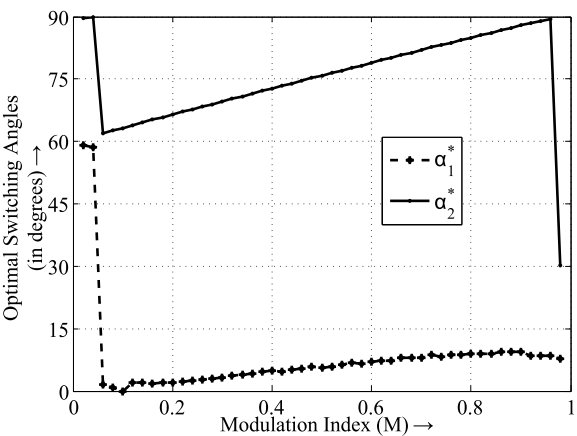

(b)

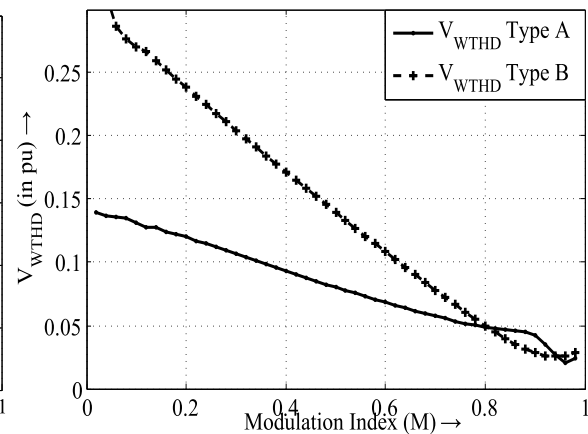

(c)

Fig. 2. Optimal switching angles for (a) type A waveform and (b) type B waveform. (c) Comparison of $V_{W T H D}$ of type A with type B waveforms for pulse number 5

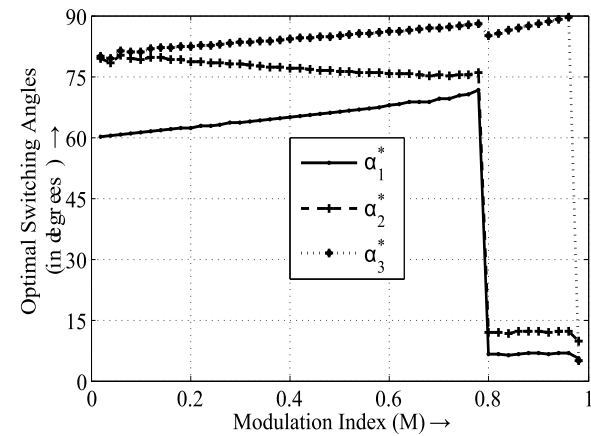

(a)

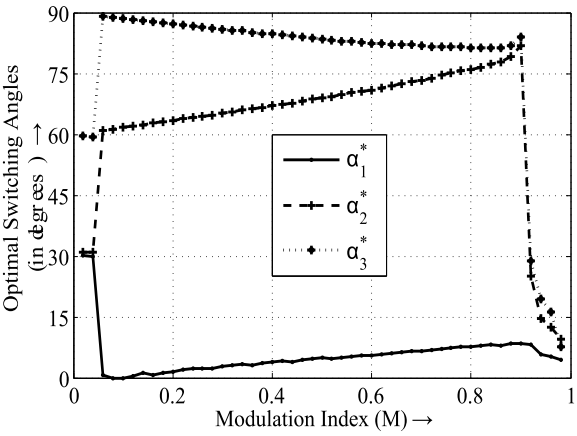

(b)

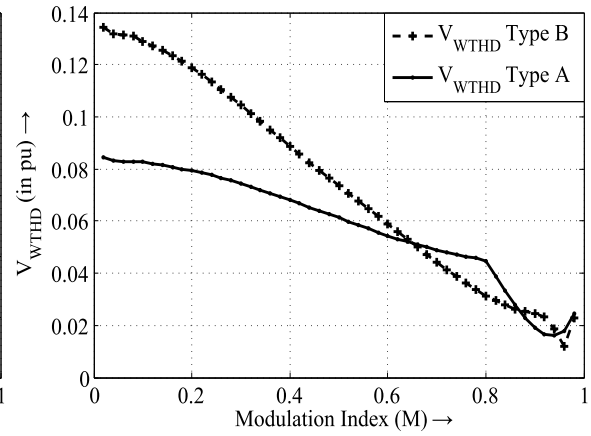

(c)

Fig. 3. Optimal switching angles for (a) type A waveform and (b) type B waveform. (c) Comparison of $V_{W T H D}$ of type A with type B waveforms for pulse number 7

minimum THD in line current. Optimal switching angles are calculated over the whole range of modulation index. Optimal switching angles are thus obtained for both types of PWM for both pulse numbers.

Performances of optimal type-A PWM and optimal type-B PWM are compared, based on simulation as well as experimental results on a $3.7 \mathrm{~kW}$ induction motor drive, at both pulse numbers of 5 and 7 . It is shown that neither type-A nor type-B is superior to the other in the whole range of modulation at any pulse number. At each $P$, optimal type-A is better than optimal type-B in certain ranges of modulation index, while the converse is true in the other ranges of modulation. Hence a combined optimal PWM is suggested, employing optimal type-A and optimal type-B PWM schemes in their respective modulation ranges of superior performance.

Finally, the optimal type-A PWM, optimal type-B PWM and the combined optimal PWM are viewed from a space vector point of view. The waveforms of the three techniques are studied in terms of the voltage vectors applied in a sector. An effort is made to understand optimality in terms of the voltage vectors applied.

\section{Optimal Pulse-Width Modulation}

Optimal PWM is usually employed at low-switching frequencies for minimization of total harmonic distortion in line current $\left(I_{T H D}\right)$ at any given modulation index $(M)$ $[1][5][6][8][9][10] . I_{T H D}$ is defined in (1) [8]

$$
I_{T H D}=\sqrt{\frac{I_{R M S}^{2}-I_{1}^{2}}{I_{1}^{2}}}=\sqrt{\frac{\sum_{n=6 k \pm 1} I_{n}^{2}}{I_{1}^{2}}} k=1,2,3 \ldots
$$

where, $I_{R M S}$ is the RMS line current; $I_{1}$ is RMS fundamental line current; $I_{n}$ is the $n^{\text {th }}$ order harmonic RMS current.

Since $I_{T H D}$ is dependent on machine parameters, the weighted total harmonic distortion of line to line voltage $\left(V_{W T H D}\right)$ is considered here for minimization, which is a measure of $I_{T H D}$ [8]. $V_{W T H D}$ of line to line voltage is given as [5]

$$
V_{W T H D}=\sqrt{\frac{\sum_{n=6 k \pm 1} F_{n}^{2} / n^{2}}{F_{1}^{2}}} k=1,2,3 \ldots
$$

where, $F_{1}$ is the peak fundamental voltage and $F_{n}$ is the peak $n^{\text {th }}$ harmonic voltage.

The amplitude of $F_{n}$ for pulse number 5 (i.e. 2 switching angles, $\alpha_{1}$ and $\alpha_{2}$ per quarter cycle), considering type-A and type-B waveforms, is given by (3) and (4), respectively, where 
$V_{d c}$ is the DC bus voltage [9]

$$
\begin{array}{r}
F_{n}=\left(\frac{2 V_{d c}}{n \pi}\right)\left[1-2 \cos \left(n \alpha_{1}\right)+2 \cos \left(n \alpha_{2}\right)\right] \\
F_{n}=\left(\frac{2 V_{d c}}{n \pi}\right)\left[-1+2 \cos \left(n \alpha_{1}\right)-2 \cos \left(n \alpha_{2}\right)\right] \\
n=1,5,7,11,13 \ldots .
\end{array}
$$

The corresponding expression for pulse number 7 (i.e. 3 switching angles, $\alpha_{1}, \alpha_{2}$ and $\alpha_{3}$ per quarter cycle), for typeA and type-B waveforms, are given by (5) and (6), respectively [9]

$$
\begin{array}{r}
F_{n}=\left(\frac{2 V_{d c}}{n \pi}\right)\left[1-2 \cos \left(n \alpha_{1}\right)+2 \cos \left(n \alpha_{2}\right)-2 \cos \left(n \alpha_{3}\right)\right] \\
F_{n}=\left(\frac{2 V_{d c}}{n \pi}\right)\left[-1+2 \cos \left(n \alpha_{1}\right)-2 \cos \left(n \alpha_{2}\right)+2 \cos \left(n \alpha_{3}\right)\right] \\
n=1,5,7,11,13 \ldots .
\end{array}
$$

$V_{W T H D}$ is minimized subject to the constraint that the modulation index $M$ equals the desired modulation index $M^{*}$ as shown by (7). Here, modulation index is the fundamental voltage normalized with respect to $\frac{2 V_{d c}}{\pi}$. The switching angle constraint is given by the inequality in (8) for $P=5$ and by (9) for $P=7$.

$$
\begin{aligned}
M & =M^{*} \\
0 & \leq \alpha_{1} \leq \alpha_{2} \leq \frac{\pi}{2} \\
0 & \leq \alpha_{1} \leq \alpha_{2} \leq \alpha_{3} \leq \frac{\pi}{2}
\end{aligned}
$$

First considering the type-A waveform of $P=5$, the optimal switching angles $\alpha_{1}^{*}$ and $\alpha_{2}^{*}$ are evaluated to minimize $V_{W T H D}$ as defined by (2) and (3) subject to the constraint in (7) and (8). These optimal angles are plotted against $M$ in Fig.2(a). Similarly, for type-B waveform of $P=5$, the optimal switching angles are determined so as to minimize $V_{W T H D}$ defined by (2) and (4), subject to the constraints in (7) and (8). These optimal switching angles are shown against $M$ in Fig.2(b). The $V_{W T H D}$ values pertaining to the optimal type-A and optimal type-B waveforms are compared in Fig.2(c).

Similarly, the results of optimization for $P=7$ are shown in Figs.3(a), 3(b) and 3(c). $V_{W T H D}$ is minimized subject to the constraints in (7) and (9). $V_{W T H D}$ is given by (2) and (5) for type-A waveform, and by (2) and (6) for type-B waveform. The optimal switching angles of the two types are presented in Fig.3(a) and Fig.3(b), respectively. A comparison of $V_{W T H D}$ of the optimal type-A and optimal type-B is presented in Fig.3(c).

As shown by Fig.2(c) and Fig.3(c), neither optimal type-A nor optimal type-B is superior over the whole range of $M$ at either pulse numbers. One scheme is better than the other, and vice versa, in different ranges of modulation index. Hence, a combined optimal PWM is proposed. The $V_{W T H D}$ of this proposed combined optimal PWM is better than the corresponding PWM scheme in literature [11] as shown Fig.4(a) and Fig.4(b). The improvement in harmonic distortion can be

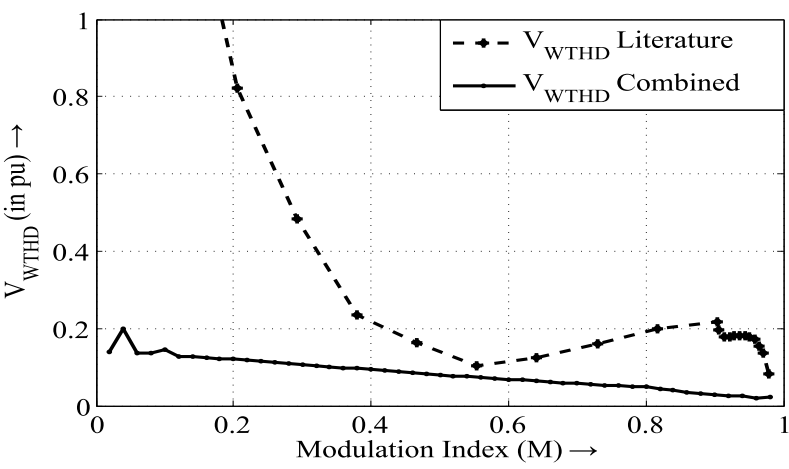

(a)

(6)

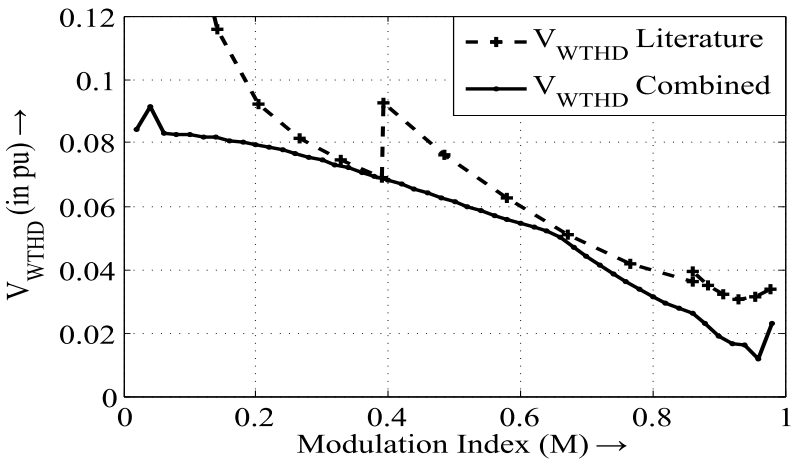

(b)

Fig. 4. Comparison of $V_{W T H D}$ of combined optimal PWM with that presented in literature [12] for pulse numbers of (a) 5 and (b) 7

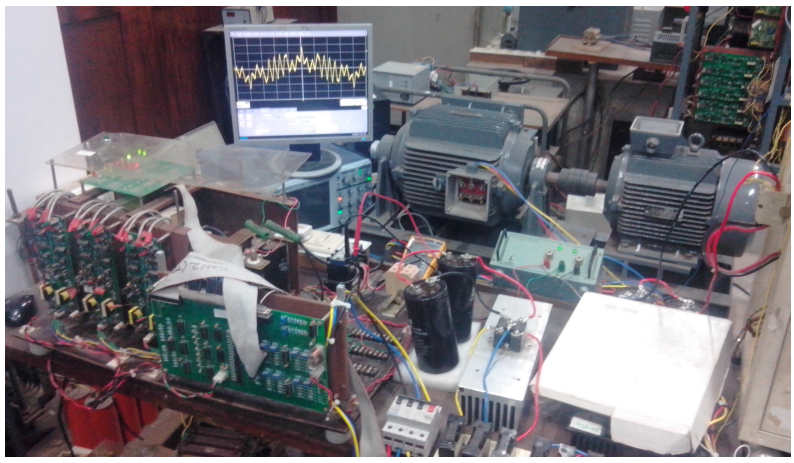

Fig. 5. Experimental set-up showing the 10kVA inverter and $3.7 \mathrm{~kW}$ induction motor

attributed to a more rigorous search process over the entire solution space here than in [11].

\section{Simulation And EXPERIMENTAl Results}

Fig.7 shows the experimental set-up used in this paper. A three-phase, $400 \mathrm{~V}, 3.7 \mathrm{~kW}, 1460 \mathrm{rpm}, 50 \mathrm{~Hz}$, star/delta squirrelcage induction motor (SCIM) is used whose parameters are given in Table I. The motor is driven by three-phase, 10kVA inverter in open-loop V/f control. FPGA based CYCLONE II controller board is used to control the converter. DC bus voltage is maintained at $520 \mathrm{~V}$ using a three-phase diode bridge rectifier with an autotransformer at the input side. The complete model is simulated on MATLAB/Simulink with a 


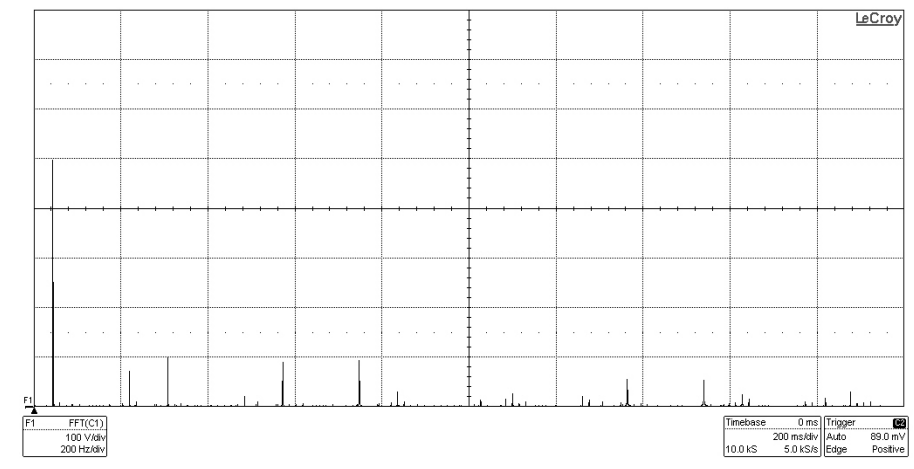

(a)

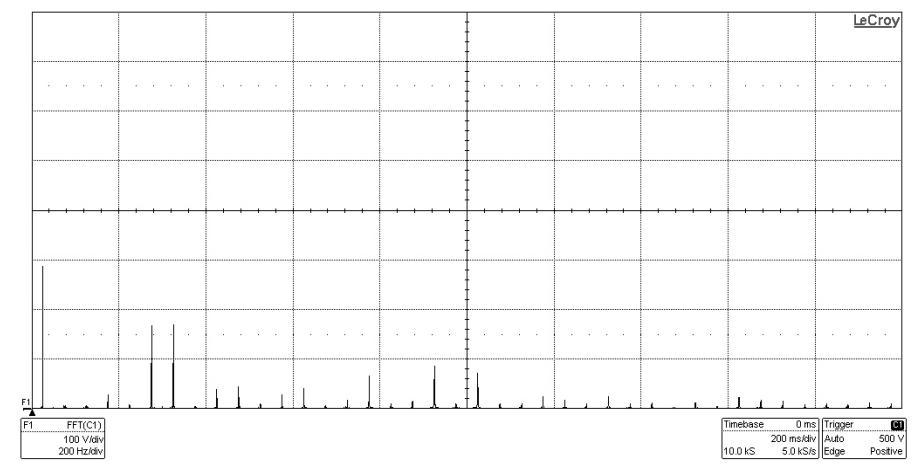

(c)

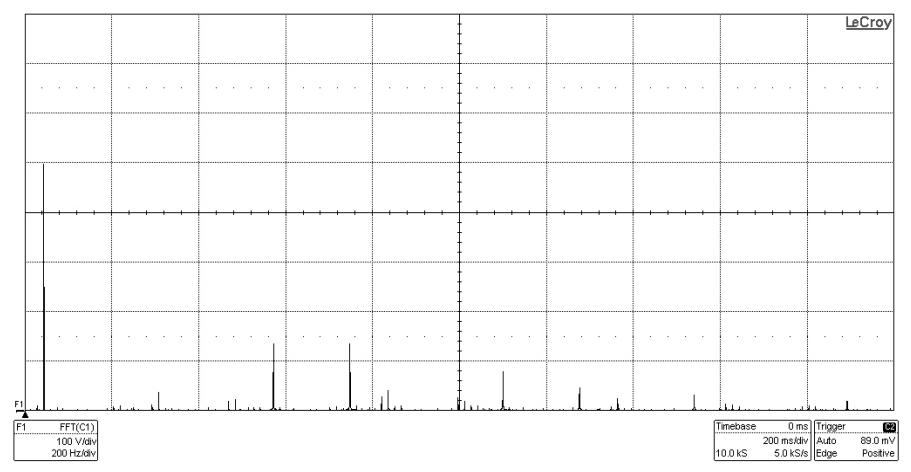

(b)

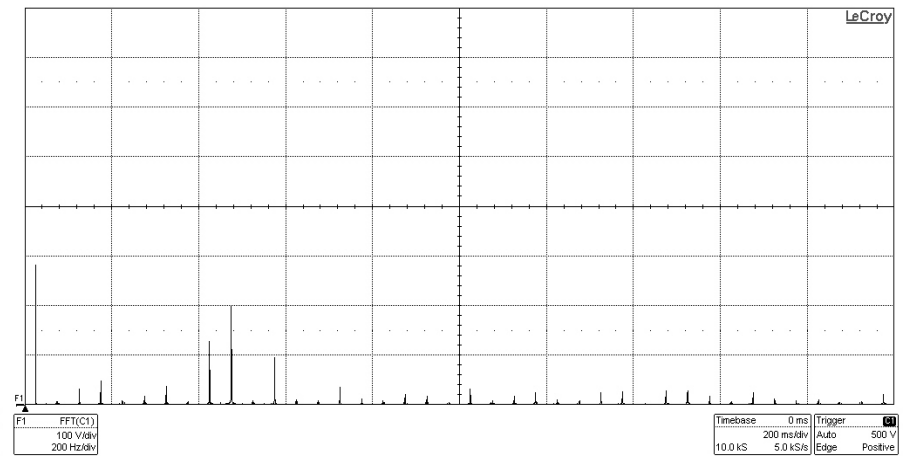

(d)

Fig. 6. Measured harmonic spectra of line-line voltage with optimal PWM (a) $M=0.88, f_{1}=44 \mathrm{~Hz}, P=5$, type A, $V_{W T H D}=0.0449$ (b) $M=0.88$, $f_{1}=44 \mathrm{~Hz}, P=5$, type B, $V_{W T H D}=0.0313$ (c) $M=0.50, f_{1}=25 \mathrm{~Hz}, P=7$, type A, $V_{W T H D}=0.0613$ (d) $M=0.50, f_{1}=44 \mathrm{~Hz}, P=7$, type $\mathrm{B}, V_{W T H D}=0.0743$; (scale: $100 \mathrm{~V} /$ div. and $200 \mathrm{~Hz} /$ div.)

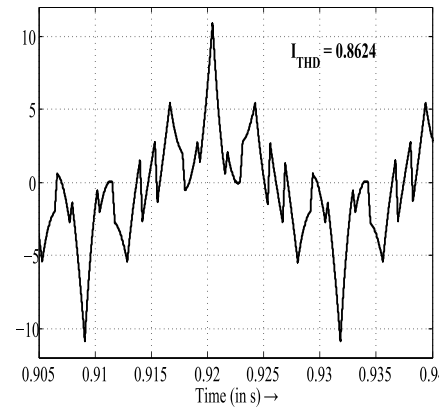

(a)

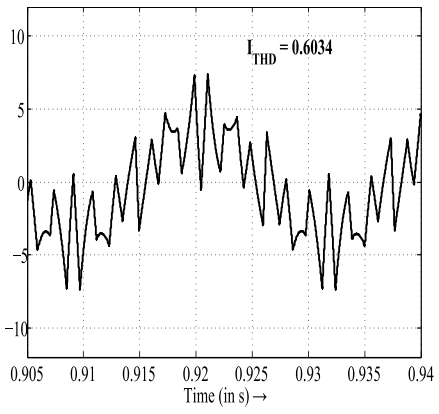

(b)

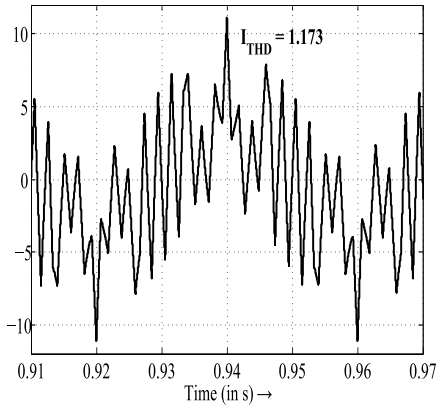

(c)

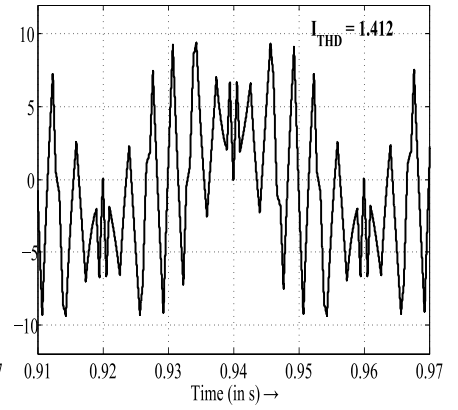

(d)

Fig. 7. Simulated R-phase current waveforms corresponding to Fig.6 (scale: 1 A/div.)

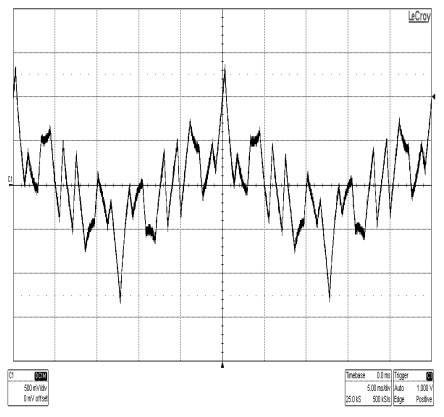

(a)

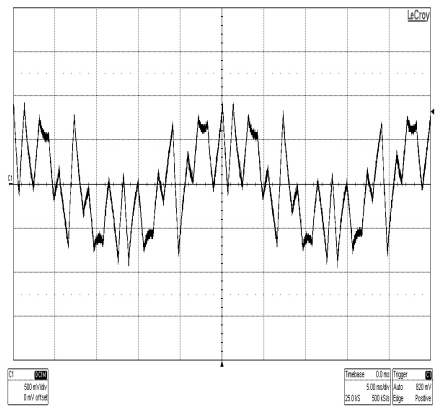

(b)

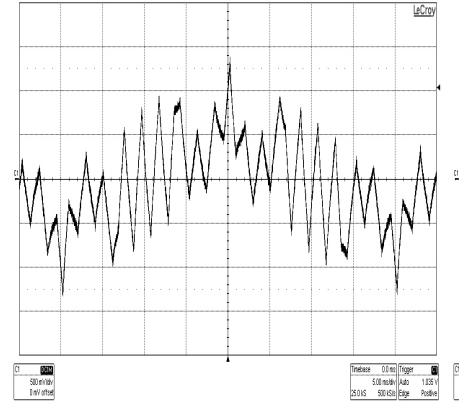

(c)

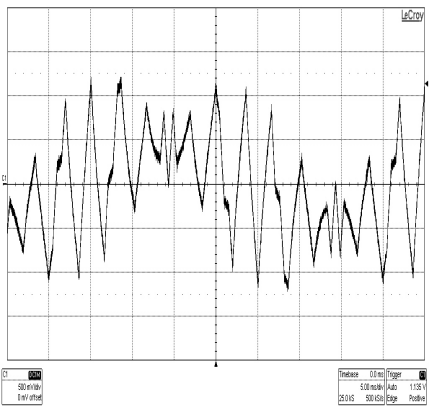

(d)

Fig. 8. Measured R-phase current waveforms corresponding to Fig.6. Measured $I_{T H D}$ values are (a) 0.8134 (b)0.5972 (c)1.0896 and (d)1.3667; (scale: $4.25 \mathrm{~A} /$ div.) 


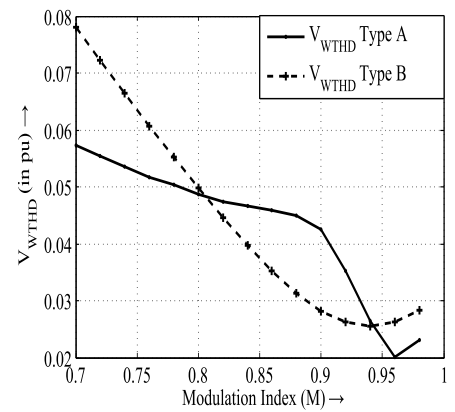

(a)

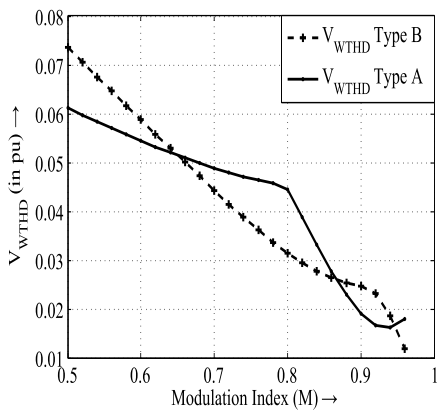

(b)

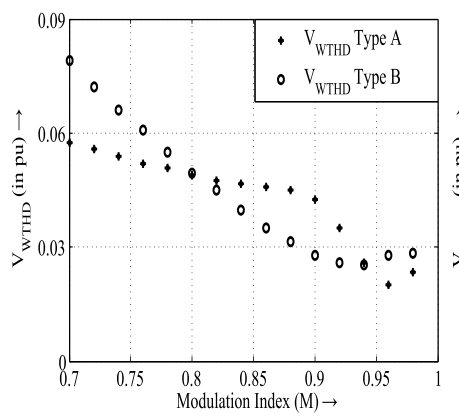

(c)

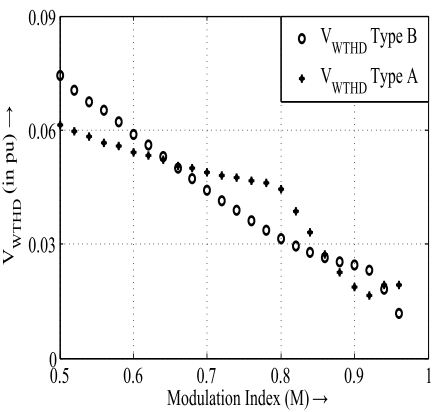

(d)

Fig. 9. Comparison of $V_{W T H D}$ for optimal type A and optimal type B PWM (a) simulated values for $P=5$ (b) simulated values for $P=7$ (c) measured values for $P=5$ and (d) measured values for $P=7$

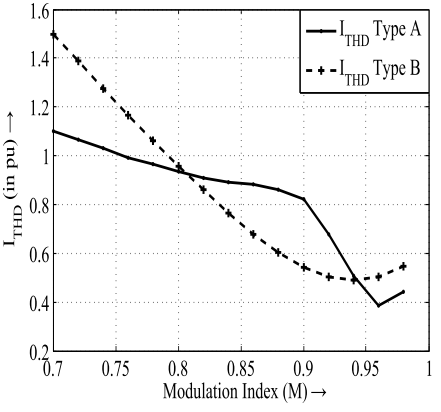

(a)

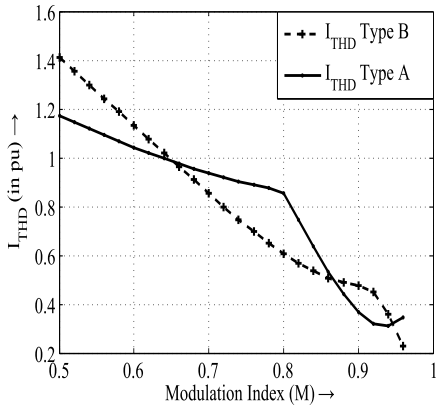

(b)

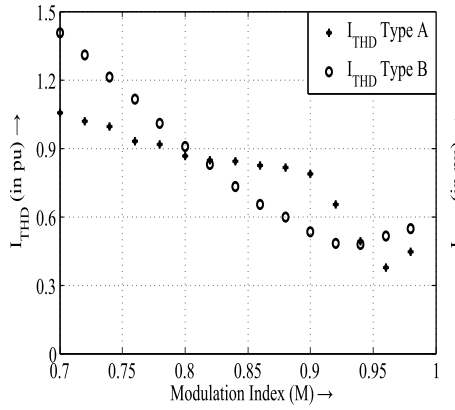

(c)

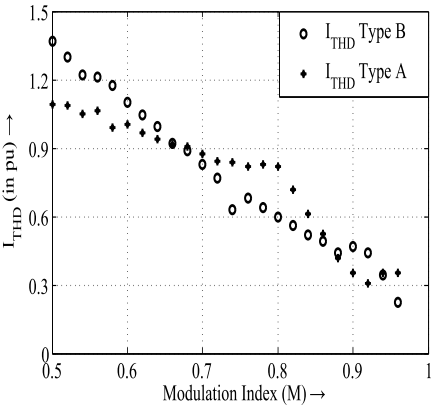

(d)

Fig. 10. Comparison of $I_{T H D}$ for optimal type A and optimal type B PWM (a) simulated values for $P=5$ (b) simulated values for $P=7$ (c) measured values for $P=5$ and (d) measured values for $P=7$

TABLE I

PARAMETERS OF INDUCTION MOTOR

\begin{tabular}{|c|c|}
\hline Parameter & Value \\
\hline Stator Resistance, $R_{s}$ & $1.4 \Omega$ \\
\hline Rotor Resistance, $R_{r}$ & $1.96 \Omega$ \\
\hline Stator Inductance, $L_{s}$ & $0.2844 \mathrm{H}$ \\
\hline Rotor Inductance, $L_{r}$ & $0.2844 \mathrm{H}$ \\
\hline Magnetizing Inductance, $L_{o}$ & $0.277 \mathrm{H}$ \\
\hline
\end{tabular}

standard induction motor model [12].

\section{A. Harmonic Spectra}

Fig.6(a) and Fig.6(b) show the measured harmonic spectra of line to line voltage $\left(v_{R Y}\right)$ for type A and type B PWM waveforms, respectively, at $M=0.88$ for $P=5$. Reduction in $5^{\text {th }}$ and $7^{\text {th }}$ harmonics can be seen with optimal type-B PWM as compared to optimal type-A PWM. Also, $V_{W T H D}$ is found to be reduced with optimal type-B PWM. However, at a different modulation index of 0.5 , optimal type-A PWM is found to be better than optimal type-B for $P=7$ as seen from Figs.6(c) and 6(d). Theoretical harmonic spectra of $v_{R Y}$ are not shown due to space constraint.

\section{B. Line Current Waveform}

Figs.7(a), 7(b), 7(c) and 7(d) present the simulated line current $\left(i_{R}\right)$ waveforms corresponding to Figs.6(a), 6(b), 6(c) and 6(d), respectively. The corresponding measured line current waveforms are shown in Figs. 8(a), 8(b), 8(c) and $8(\mathrm{~d})$, respectively. The simulated and measured line current waveforms in Fig.7 and Fig.8 agree well. Figs.7(a), 7(b), 8(a) and 8 (b) confirm that optimal type-B is better than optimal type-A at $M=0.88$ for $P=5$. Similarly, Figs.7(c), 7(d), $8(\mathrm{c})$ and $8(\mathrm{~d})$ confirm the reduction in harmonic distortion with type-A over type-B at $M=0.5$ for $P=7$.

\section{C. $V_{W T H D}$ and $I_{T H D}$ Comparison}

Further, $V_{W T H D}$ and $I_{T H D}$ pertaining to optimal type-A and optimal type-B PWM are compared through simulations and experiments over a range of $M$ for $P=5$ and 7 . Figs.9(a) and 9(b) compare the simulated $V_{W T H D}$ values for $P=5$ and $P=7$, respectively, while, Figs.9(c)and 9(d) present the measured $V_{W T H D}$ for $P=5$ and $P=7$, respectively. Comparison of simulated $I_{T H D}$ values of type-A and type-B waveform is presented in Fig.10(a) and Fig.10(b) for $P=5$ and $P=7$, respectively. The measured $I_{T H D}$ is compared similarly in Figs.10(c) and 10(d). The simulation and experimental results are found to be in close agreement with the theoretical predictions in Fig.2(c) and Fig.3(c).

\section{Discussion}

Three-phase pole voltages can be viewed in terms of inverter states. Fig.11 shows the eight inverter states (i.e. six active states and two zero states) [7]. The complete fundamental cycle is divided into six sectors [7]. Optimal type-A and 


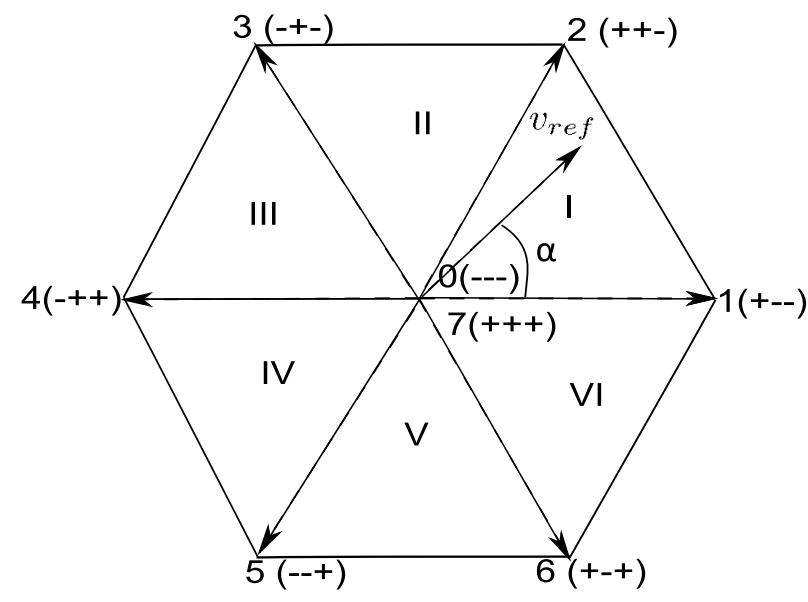

Fig. 11. Space vector representation of switching states for two level inverter

TABLE II

SEQUENCE OF VECTORS APPLIED IN SECTOR I FOR $P=5$

\begin{tabular}{|c|c|c|c|}
\hline \multirow{2}{*}{$\begin{array}{c}\text { Modulation index } \\
(M)\end{array}$} & \multicolumn{3}{|c|}{ Vector sequence } \\
\cline { 2 - 4 } & Type A & Type B & Combined optimal \\
\hline $0<M \leq 0.8$ & $101-272$ & $012-127$ & $101-272$ \\
\hline $0.8<M \leq 0.88$ & $101-272$ & $012-127$ & $012-127$ \\
\hline $0.88<M \leq 0.94$ & $121-212$ & $012-127$ & $012-127$ \\
\hline $0.94<M<1.0$ & $121-212$ & $012-127$ & $121-212$ \\
\hline
\end{tabular}

optimal type-B PWM waveforms are analysed from the space vector point of view. Tables II and III present the sequence of vectors applied by optimal type-A PWM, optimal type-B PWM and combined optimal PWM in sector I for the complete range of modulation index.

In sector I, the inverter states applied are found to be only $0,1,2$ and 7 in all the optimal PWM methods. Further, the sequence of inverter states within sector I changes from one modulation index range to another for each optimal PWM as shown in Table II and Table III.

The combined optimal PWM is shown to have all but one switching transitions between a zero state and an active state in each sector at low modulation indices. As the modulation index increases, the number of transitions between the zero state and active state (say 0 and 1 ) reduces progressively; the corresponding number of transitions between the two active states increases (i.e. between 1 and 2). At high modulation indices close to six-step operation, all switching transitions in a sector are between the two active vectors (i.e. 1 and 2).

TABLE III

SEQUENCE OF VECTORS APPLIED IN SECTOR I FOR $P=7$

\begin{tabular}{|c|c|c|c|}
\hline Modulation index & \multicolumn{3}{|c|}{ Vector sequence } \\
\cline { 2 - 4 }$(M)$ & Type A & Type B & Combined optimal \\
\hline $0<M \leq 0.64$ & $0101-2727$ & $1012-1272$ & $0101-2727$ \\
\hline $0.64<M \leq 0.78$ & $0101-2727$ & $1012-1272$ & $1012-1272$ \\
\hline $0.78<M \leq 0.86$ & $0121-2127$ & $1012-1272$ & $1012-1272$ \\
\hline $0.86<M \leq 0.92$ & $0121-2127$ & $1012-1272$ & $0121-2127$ \\
\hline $0.92<M \leq 0.94$ & $0121-2127$ & $1212-1212$ & $0121-2127$ \\
\hline $0.94<M<1.0$ & $0121-2127$ & $1212-1212$ & $1212-1212$ \\
\hline
\end{tabular}

\section{CONClusion}

Optimal pulse width modulation to minimize line current total harmonic distortion (THD) is examined at pulse numbers of 5 and 7 , considering both type-A and type-B waveforms. Performance of optimal type-A and optimal type-B PWM schemes are compared at both pulse numbers. The comparison is based on simulation results as well as experimental results, on a $3.7 \mathrm{~kW}$ induction motor drive. Neither, optimal type-A nor optimal type-B is better than the other over the whole range modulation index at any pulse number. The two schemes have their own modulation ranges of superior performance. Hence, a combined optimal PWM scheme is proposed.

The optimal type-A PWM, the optimal type-B PWM and the combined optimal PWM are analysed from the space vector perspective. It is observed that only the two nearest active vectors are applied in all three optimal PWM schemes. In case of combined optimal PWM, the number of switching transitions between an active vector and a zero vector reduces progressively with increase in modulation index. Close to sixstep operation, all the switching transitions are found to be between the active vectors only.

\section{REFERENCES}

[1] A. K. Rathore, J. Holtz and T. Boller, "Generalized Optimal Pulsewidth Modulation of Multilevel Inverters for Low-Switching-Frequency Control of Medium-Voltage High-Power Industrial AC Drives ," IEEE Trans. Ind. Electron., Vol. 60, No. 10, Oct. 2013, pp. 4215-4224.

[2] J. A. Pontt, J. R. Rodriguez, A. Liendo, P. Newman and J. Holtz "Network Friendly Low-Switching-Frequency Multipulse High Power ThreeLevel PWM Rectifier ," IEEE Trans. Ind. Electron., Vol. 56, No. 4, Apr. 2009, pp. 1254-1262.

[3] J. Shen, S. Schroder, H. Stagge and R. W. De Doncker, "Impact of Modulation Schemes on the Power Capability of High-Power Converters with Low Pulse Ratios ," IEEE Trans. Pow. Electron., Vol. 29, No. 11 Nov. 2014, pp. 5696-5705.

[4] M. Sharifzade1, H. Vahedi, A. Sheikholeslami1, H. Ghoreishy, K. AI-Haddad, "Selective Harmonic Elimination Modulation Technique Applied on Four-Leg NPC ," Proc. on 23rd Intl. Symp. on Ind. Electron. (ISIE), Turkey, June 2014, pp. 2167-2172.

[5] N. Yosefpoor, S. A. Fathi, N. Farokhina and H. A. Abyaneh, "THD Minimisation Applied Directly on the Line-to-Line Voltage of Multilevel Inverters," IEEE Trans. Ind. Electron., Vol. 59, No. 1, Jan. 2008, pp. 373-380.

[6] L. Liyi, G. Tan, J. Liu and B. Kou, "An Optimal Pulse Width Modulation Method for High-speed Permanent Magnet Synchronous Motor," Proc. Third Intl. Conf. on Inf. Science and Tech., China, March 2013, pp. 237-244.

[7] G. Narayanan and V. T. Ranganathan, "Synchronized PWM Strategies Based on Space Vector Approach. Part 1: Principles of waveform Generation," IEE Proc. Elec. Power Appl., Vol. 146, No. 3, May 1999, pp. 267-275.

[8] A. Tripathi and G. Narayanan "Optimal Pulse Width Modulation of Voltage-Source Inverter Fed Motor Drives with Relaxation of Quarter Wave Symmetry Condition," Proc. IEEE Intl. Conf. Electron., Comp. and Comm. Technology (IEEE CONECCT), 6-7 Jan. 2014, pp. 1-6.

[9] G. S. Buja and G. B Indri, "Optimal Pulse-Width Modulation for Feeding AC Motors," IEEE Trans.Ind. Appl., Vol. IA-13, No. 1, Jan/Feb 1977, pp. 38-44.

[10] F. C. Zach and H. Ertl, "Efficiency Optimal Control for AC Drives with PWM Inverters," IEEE Trans. Ind. Appl., Vol. IA-21, No. 4, July/Aug. 1985 , pp. $987-1000$

[11] D. G. Holmes, T. A. Lipo, "Pulse Width Modulation for Power Converters Principles and Practice," IEEE Press, 2003.

[12] W. Leonhard, "Control of electrical drives," Narosa publishing house, 1992. 